\title{
HEALTH INEQUALITIES AND THE HEALTH NEEDS OF PEOPLE WITH MENTAL ILLNESS
}

\section{David Lawrence \\ Telethon Institute for Child Health Research Perth, Western Australia}

\section{Rebecca Coghlan}

Department of Public Health

University of Western Australia

This article describes a study that used the Western Australian Linked Database (WALD)— which links together major sources of health data for the population of Western Australia (WA) - to examine rates of hospitalisation and death due to physical illnesses for users of mental health services. The aim of the study was to compare the physical health of people with mental illness with that of the general population, in order to provide information that can be used in designing health promotion and disease control activities that can be tailored for people with mental illness. The results showed high mortality from all causes, both natural and unnatural. Significant morbidity associated with all main conditions was not accompanied by correspondingly high hospital use. For example, for ischaemic heart disease (IHD), while mortality was two-and-a-half times higher in people with mental illness, coronary revascularisation procedure rates were significantly lower than in the general community. These results highlight significant health inequalities, commensurate to health care needs, in this vulnerable population.

The WALD is unique in Australia and is one of a small number of combined record linkage systems in the world. While mortality in people with mental illness has been extensively studied, ${ }^{1}$ there has only been one other major study of hospitalisation rates, which dates from the $1960 \mathrm{~s}^{2}$

\section{METHODS}

The study used data from the WALD,${ }^{3}$ which links together major sources of health data for the population of WA. The main sources of data contained in the WALD are:

- Hospital Morbidity Data System (HMDS);

- Mental Health Information System (MHIS);

- WA Cancer Registry;

- WA birth and death records.

The HMDS records all separations from WA private and public hospitals since 1980 . The MHIS records all contacts with inpatient mental health services (private and public), public outpatient and community clinics, and licensed psychiatric hostels since 1966. The MHIS does not include people only seen by general practitioners or by private psychiatrists in their consulting rooms. The various databases in WALD have been linked, using probabilistic record linkage techniques, which achieve a high degree of accuracy. The resulting linked files are de-identified for research purposes. The WALD allows tracking of a person's health experience over their lifetime.
The study used data covering the 19-year period 19801998, and examined the health records of 231,311 users of mental health services, representing about eight per cent of the WA population at any time. For this group, rates of admission to hospital, diagnosis of cancer, and death were calculated and compared to the corresponding rate in the total population. Mental disorders were classified using ICD-9, as were deaths. Although all ICD9 Chapter 5 diagnoses were included on the MHIS, this study concentrates on the following conditions (with ICD9 codes shown in brackets): dementia (290), alcohol and drug disorders (291-292, 303-305), schizophrenia (295), affective psychosis (296), other psychoses (293-294, 297-299), neurotic disorder (300), personality disorder (301), adjustment reaction (309) and depressive disorder (311). Diagnoses and procedures from hospitalisations in WA were coded using ICD-9 until 1987, and thereafter using ICD-9-CM.

All rates were directly standardised using, as the population standard, the average population distribution of WA during 1980-1998, as supplied by the Australian Bureau of Statistics. ${ }^{4}$ For people with mental illness, hospitalisations were only included if they occurred after first contact with mental health services (defined as any contact with inpatient psychiatric services in a private or public hospital, or contact with public outpatient or community clinics, or residence in a psychiatric hostel, as recorded on the MHIS). Rates were calculated for people with mental illness and the population as a whole. Rate ratios were then used to compare the two. Although not shown in the figures, standard errors and 95 per cent confidence intervals were calculated for all results. All differences commented on were significant at the 95 per cent level of confidence. Although a large number of physical illnesses were considered in this study, in this short article we concentrate on ischaemic heart disease.

\section{RESULTS}

Figure 1 shows mortality rates from major causes of death for people with mental illness compared to the WA population overall. The results show excess mortality from all causes of death, both natural and unnatural. Overall, people with mental illness have a 2.5 times higher mortality than the general population, which is equivalent to a life expectancy in the 50-59 age group.

The highest increased risk of death was for suicide. People with mental illness were more than seven times as likely to commit suicide, and users of mental health services made up 45 per cent of suicides in WA in 1980-1998. However, the greatest number of excess deaths was due to IHD (16 per cent of all excess deaths in people with mental illness), double the number of excess deaths due to suicide (eight per cent). The expected number of deaths in people with mental illness was calculated by applying the general 


\section{FIGURE 1}

\section{DEATH RATES IN PEOPLE WITH MENTAL ILLNESS COMPARED TO THE REST OF THE}

POPULATION, WESTERN AUSTRALIA, 1980-1998

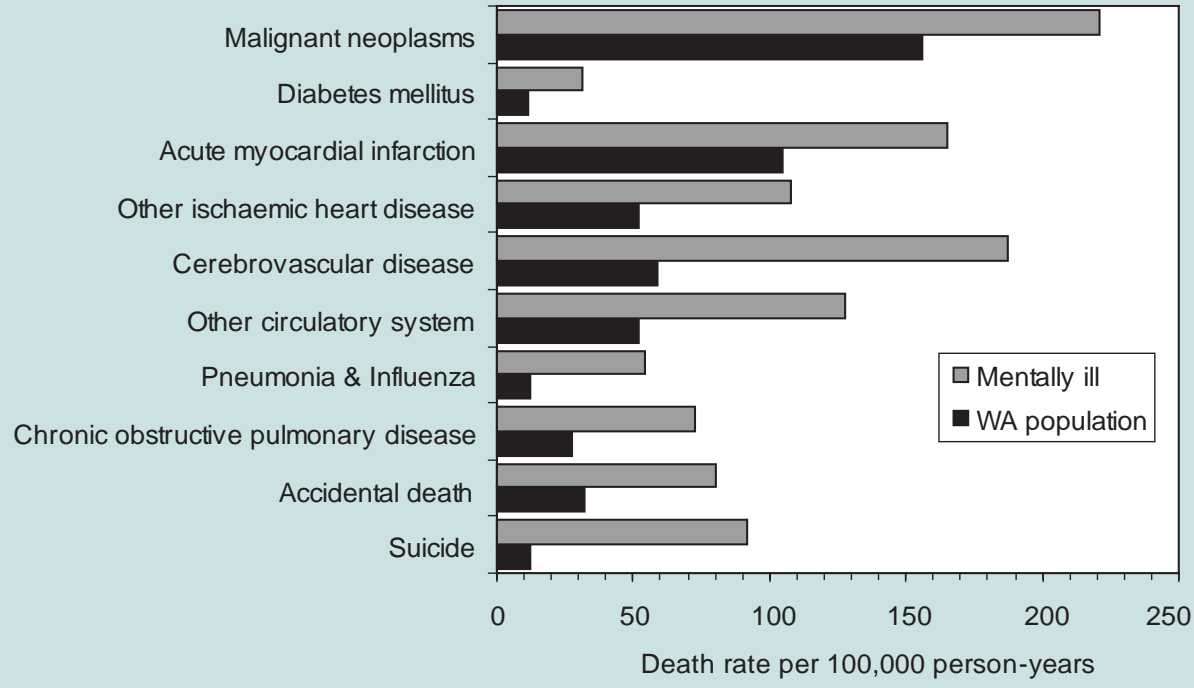

population death rate to the population of people with mental illness. Deaths above this number were called excess deaths.

Figure 2 shows rate ratios for hospitalisation, revascularisation procedures, and death rates from IHD (ICD-9 410-414), for each principal psychiatric diagnosis. Note that the mortality rate ratio (RR) for people with dementia goes beyond the scale of the graph. The RR is 3.8. People with dementia, other psychoses and depressive disorder had the highest mortality rate ratios. IHD mortality has been declining in the general population over the past 20 years. ${ }^{5}$ We found that people with mental illness have not participated in this trend. The IHD mortality rate has remained roughly constant in men with mental illness, and has been increasing among women with mental illness.

By comparison, however, the rate of admission to hospital with a principal diagnosis of IHD was very similar in people with mental illness and the general population. Only people with a neurosis or depressive disorder were more likely to be hospitalised for IHD than the general population. People with schizophrenia were 40 per cent less likely to be hospitalised for IHD.

In addition, we calculated the rate of performing coronary revascularisation procedures (including removal of coronary artery obstructions and coronary artery bypass grafts and arterial implants). People with dementia almost never underwent these procedures, and people with schizophrenia underwent them at only one-third of the rate in the general population. For most disorders, revascularisation procedure rates were low compared to the general community. Only people with neurotic disorders had an elevated rate of revascularisation procedures, while among people with adjustment reaction (ICD-9 code 309) revascularisation procedure rates were about the same as in the general population.

We also examined the most serious and commonly occurring physical health problems including cancer, stroke and other circulatory disorders, respiratory disorders, communicable diseases, and injuries. We found consistently that the excess in mortality rates was not matched by a corresponding increase in hospitalisation rates. Also, cancer incidence was almost identical in people with mental illness as the general population, but cancer mortality was 40 per cent higher in people with mental illness. ${ }^{6}$

\section{DISCUSSION}

Users of mental health services account for eight per cent of the WA population at any time. However, the ABS Survey of Mental Health and Wellbeing estimated that 19 per cent of the WA population has a diagnosable mental illness, ${ }^{7}$ but that over 60 per cent of people receive no treatment for their disorder. ${ }^{7}$ As the MHIS does not include people who are only seen by general practitioners or by private psychiatrists in their consulting rooms, the people on the MHIS most likely represent the more serious cases of mental illness.

The poor mortality results for people with mental illness are similar to general populations living in developing countries, ${ }^{8}$ and suggest serious health inequalities compared to Australians without mental illness. There is no doubt that lifestyle and behavioural factors associated with mental illness affect physical illness. Smoking is common. According to ABS data, 43 per cent of Western Australians with a mental disorder are current smokers 
compared to 24 per cent of those without a mental disorder. ${ }^{7}$ In people with psychotic disorders smoking rates are even higher- 73 per cent of men and 56 per cent of women were current smokers in a recent study. ${ }^{9}$ Similarly alcohol and drug use problems are more common in people with mental illness. Poor diets and lack of exercise are also significant problems. Public health campaigns have been instrumental in the lowering of cardiovascular mortality in the general Australian population; however, these campaigns appear to have had little effect on people with mental illness. For example, there are few programs aimed at reducing smoking in people with mental illness.

There is more to the issue than lifestyle factors. The comparison of procedure rates, hospitalisation rates, and death rates, strongly suggests that health services have not met the physical health needs of people with mental illness. This could be due to issues of access, stigma, lack of appropriate services, and communication difficulties. ${ }^{10}$ Mental health services are often provided by separate groups of practitioners to physical health services. It is unclear if all psychiatrists see their role as including management of the physical wellbeing of people with mental illness. Mental health services may miss physical illnesses as they focus on psychiatric symptoms and may regard complaints of physical symptoms as psychosomatic. ${ }^{11,12,13}$ At the same time, do people with mental illness receive an appropriate level of medical care from general practitioners and other health services? People under psychiatric care may not be seen concurrently by general practitioners and some people with a mental illness may not have a regular general practitioner. ${ }^{14,15}$

WA is uniquely privileged to have the infrastructure for medical record linkage of data for the whole state population. The size and the stability of the population have made this possible. However, there is no reason to believe that there are major differences in mental health care and service delivery in WA compared to other states and territories, and there is no reason to believe these results would not be reproduced in other states were the data available.

People with mental illness are a marginalised and stigmatised group with extremely poor health outcomes. This group deserves a higher level of care of their physical health than the general community, in proportion to their greater health needs, but they may actually be receiving less. This suggests inequality in health service access and provision that deserves to be investigated and resolved.

\section{ACKNOWLEDGEMENTS}

This study was funded by the National Health and Medical Research Council. The construction of the WA Linked Database was funded by the Lotteries Commission of Western Australia.

\section{FIGURE 2}

IHD HOSPITALISATION, REVASCULARISATION PROCEDURE AND DEATH RATES, BY PRINCIPAL PSYCHIATRIC DIAGNOSIS, WESTERN AUSTRALIA, 1980-1998

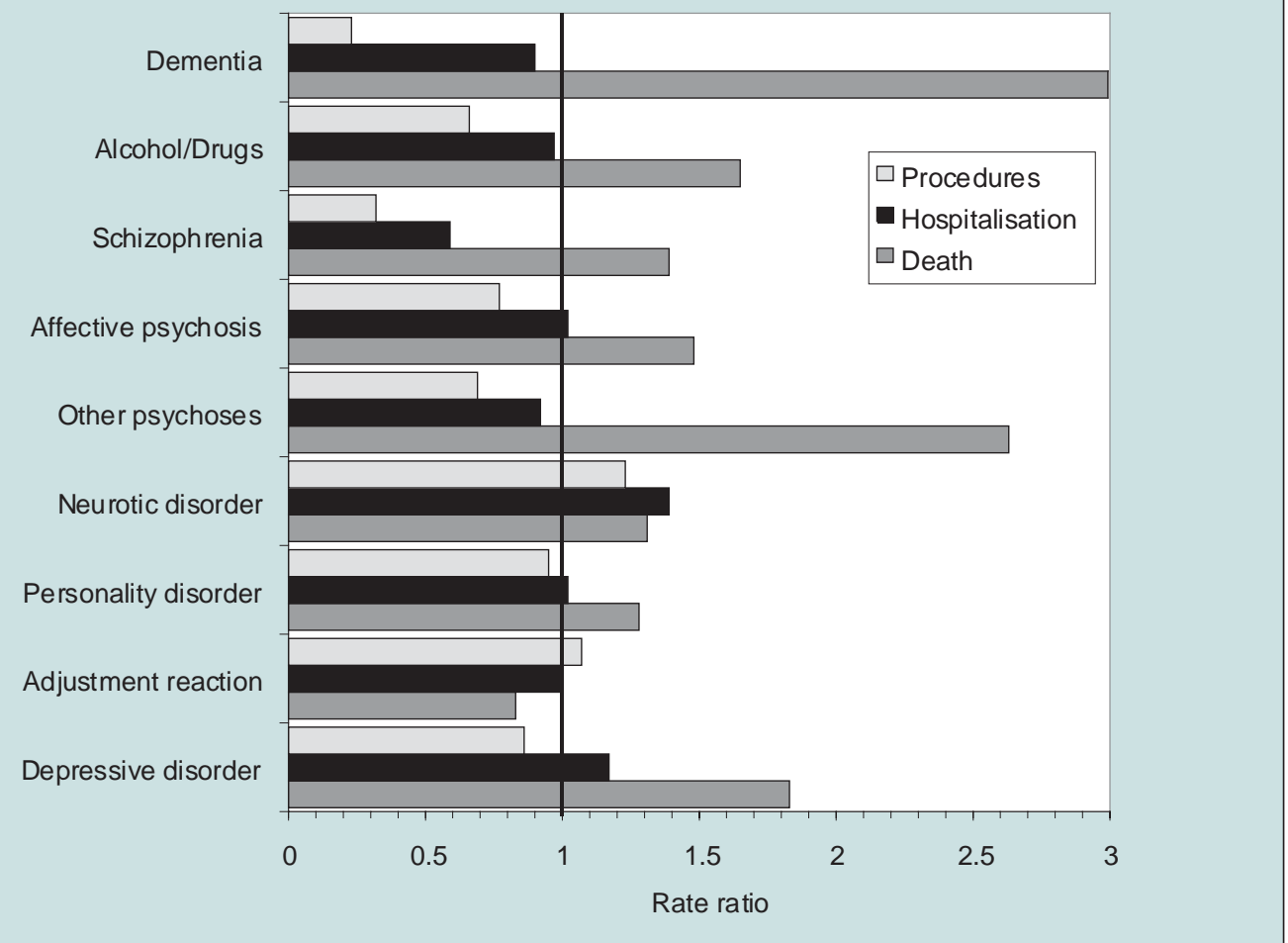


Further information regarding this study can be downloaded from the Web site www.dph.uwa.edu.au by following the links: Research Programs $\rightarrow$ Centre for Health Services Research $\rightarrow$ Duty to Care.

\section{REFERENCES}

1. Harris EC, Barraclough B. Excess mortality of mental disorder. Br J Psychiatry 1998; 173: 11-53.

2. Baldwin JA. Schizophrenia and physical disease. Psychol Med 1979; 9: 611-618.

3. Holman CDJ, Bass AJ, Rouse IL, Hobbs MST. Populationbased linkage of health records in Western Australia: development of a health services research linked database. Aust N Z J Public Health 1999; 23: 453-459.

4. Australian Bureau of Statistics. Population by age and sex, Western Australia. ABS Catalogue no. 3235.5. Canberra: Australian Bureau of Statistics, 1980-1998.

5. Beaglehole R. Stewart AW, Jackson R, Dobson AJ. McElduff P. D'Este K. Heller RF. Jamrozik KD. Hobbs MS. Parsons R. Broadhurst R. Declining rates of coronary heart disease in New Zealand and Australia. Am J Epidemiology 1997; 145: 707-13.

6. Lawrence D, Holman CDJ, Jablensky AV, Threlfall TJ, Fuller SA. Excess cancer mortality in Western Australian psychiatric patients due to higher case fatality rates. Acta Psychiatr Scand 2000; 101: 382-388.
7. Australian Bureau of Statistics. Mental Health and Wellbeing: Profile of Adults Western Australia 1997-1998. ABS Catalogue no. 4326.5. Canberra: Australian Bureau of Statistics. 1999.

8. World Health Organization. World Health Statistics Annual 1996. Geneva: World Health Organization, 1998.

9. Jablensky A, McGrath J, Herrman H, Castle D, Gureje O, Morgan V. National survey of mental health and wellbeing. Report 4. People living with psychotic illness: an Australian study. Canberra: Commonwealth Department of Health and Aged Care, 1999: 41.

10. Druss BG, Bradford DW, Rosenheck RA, Radford MJ, Krumholz HM. Mental disorders and use of cardiovascular procedures after myocardial infarction. JAMA 2000; 283: 506511.

11. Koran LM, Sox HC, Marton KI, Moltzen S, Sox CH, Kramer HC, Imai K, Kelsey TG, Rose TG, Levin LC, Chandra S. Medical evaluation of psychiatric patients. I. Results in a state mental health system. Arch Gen Psychiatry 1989; 46: 733740.

12. Koranyi EK. Morbidity and rate of undiagnosed physical illnesses in a psychiatric clinic population. Arch Gen Psychiatry 1979; 36: 414-419.

13. Anath J. Physical illness and psychiatric disorders. Compr Psychiatry 1984; 25: 586-593.

14. Goodwin JM, Goodwin JS, Kellner R. Psychiatric symptoms in disliked medical patients. JAMA 1979; 241: 1117-1120.

15. Kendrick T. Cardiovascular and respiratory risk factors and symptoms among general practice patients with long-term mental illness. Br J Psychiatry 1996; 169: 733-739. 똘

\section{COURT DIVERSION IN NSW FOR PEOPLE WITH MENTAL HEALTH PROBLEMS AND DISORDERS}

\section{David Greenberg and Ben Nielsen \\ NSW Statewide Community \& Court Liaison Service Corrections Health Service}

There are significantly higher prevalence rates of complex and severe mental health problems and disorders in correctional centres, both Australia-wide and internationally, compared to the general population. Recent evidence from the literature suggest that, in the United States, 6-15 per cent of people in remand prisons and $10-15$ per cent in state prisons have a serious mental disorder. ${ }^{1}$ Comparable figures are reported for the United Kingdom, with prevalence rates of 5-10 per cent among those on remand, ${ }^{2}$ and up to 14 per cent among those who have been sentenced. ${ }^{3}$ Similar prevalence estimates have been quoted in studies in Australia and New Zealand. ${ }^{4}$

During 1996-97, the Corrections Health Service and the NSW Department of Health undertook a detailed study of the health status of inmates in NSW correctional centres. Among inmates, it was reported that approximately one third of males and half of females had a history of mental health assessment and/or treatment by a psychiatrist or a psychologist.
Difficulties in delivering mental health services in a prison environment have lead to calls for improved solutions to the delivery of psychiatric services. One possible alternative comes from an international trend to develop court-based liaison programs for individuals with psychiatric disorders. These programs divert individuals with mental health problems and disorders from court settings. This article describes the NSW Statewide Community and Court Liaison Service (SCCS), which is a new initiative in court liaison and diversion based on international trends in the development of forensic psychiatric services.

\section{NSW STATEWIDE COMMUNITY AND COURT LIAISON SERVICE}

The SCCS is available to those who are charged with minor offences, where the process of prosecution has begun (that is, pre-trial), and who appear at the local Magistrate's Courts. Currently, the SCCS operates in seven metropolitan and rural courts in NSW; it is envisaged that the service will expand to include a further five courts at the end of 2002. 